\title{
Acute Remapping within the Motor System Induced by Low- Frequency Repetitive Transcranial Magnetic Stimulation
}

\author{
Lucy Lee, ${ }^{1}$ Hartwig R. Siebner, ${ }^{2,3}$ James B. Rowe, ${ }^{1,4}$ Vincenzo Rizzo, ${ }^{2,5}$ John C. Rothwell, ${ }^{2}$ Richard S. J. Frackowiak, ${ }^{1}$ and \\ Karl J. Friston ${ }^{1}$ \\ ${ }^{1}$ Wellcome Department of Imaging Neuroscience and ${ }^{2}$ Sobell Department of Motor Neuroscience and Movement Disorders, Institute of Neurology, \\ University College London, London, WC1N 3BG United Kingdom, ${ }^{3}$ Department of Neurology, Christian-Albrechts-University, Kiel, D-24105 Germany, \\ ${ }^{4}$ Department of Neurology, National Hospital for Neurology and Neurosurgery, London, WC1N 3BG United Kingdom, and ${ }^{5}$ Department of Neuroscience, \\ Psychiatric and Anesthesiological Sciences, University of Messina, Messina, I-98125 Italy
}

\begin{abstract}
Repetitive transcranial magnetic stimulation (rTMS) of human primary motor cortex $\left(\mathrm{M}_{1}\right)$ changes cortical excitability at the site of stimulation and at distant sites without affecting simple motor performance. The aim of this study was to explore how rTMS changes regional excitability and how the motor system compensates for these changes. Using functional brain imaging, activation was mapped at rest and during freely selected finger movements after $30 \mathrm{~min}$ of $1 \mathrm{~Hz}$ rTMS. rTMS increased synaptic activity in the stimulated left $\mathrm{M}_{1}$ and induced widespread changes in activity throughout areas engaged by the task. In particular, movement-related activity in the premotor cortex of the nonstimulated hemisphere increased after $1 \mathrm{~Hz}$ rTMS. Analyses of effective connectivity confirmed that the stimulated part of $\mathrm{M}_{1}$ became less responsive to input from premotor and mesial motor areas. Conversely, after rTMS our results were consistent with increased coupling between an inferomedial portion of left $\mathrm{M}_{1}$ and anterior motor areas. These results are important for three reasons. First, they show changes in motor excitability to central inputs from other cortical areas (as opposed to peripheral or exogenous inputs used in previous studies). Second, they suggest that maintenance of task performance may involve activation of premotor areas contralateral to the site of rTMS, similar to that seen in stroke patients. Third, changes in motor activations at the site of rTMS suggest an rTMS-induced remodeling of motor representations during movement. This remapping may provide a neural substrate for acute compensatory plasticity of the motor system in response to focal lesions such as stroke.
\end{abstract}

Key words: rTMS; functional imaging; plasticity; effective connectivity; motor representation; synaptic efficacy

\section{Introduction}

Repetitive transcranial magnetic stimulation (rTMS) causes immediate and lasting changes in cortical excitability at the site of stimulation and at distant sites (Siebner and Rothwell, 2002). The effects of low-frequency $(\leq 1 \mathrm{~Hz})$ rTMS to the sensorimotor hand area on cortical excitability have been investigated with various methods. These studies reveal a complex pattern of interactions among different sets of cortical neurons. rTMS at $1 \mathrm{~Hz}$ modulates the excitability of corticospinal projections from the site of stimulation, indexed by reduced amplitude of motor evoked potentials in relaxed hand muscles (Chen et al., 1997; Maeda et al., 2000; Touge et al., 2001; Romero et al., 2002; Tsuji and Rothwell, 2002). rTMS at $1 \mathrm{~Hz}$ reduces the amplitude of the long-latency stretch reflex (Tsuji and Rothwell, 2002). This may reflect decreased excitability of corticospinal projections or reduced sensitivity of primary motor hand area to sensory afferents i.e., corticocortical inputs. In addition to a reduced corticospinal output and an attenuated response to sensory input, intracortical neuronal processing within the sensorimotor hand area is modified by $1 \mathrm{~Hz}$ rTMS. Using the paired-pulse paradigm of Kujirai et al.

\footnotetext{
Received Jan. 24, 2003; revised March 20, 2003; accepted March 24, 2003.

This work was supported by the Wellcome Trust (L.L., J.B.R., R.S.J.F., K.J.F.), the Medical Research Council (J.C.R.), Deutsche Forschungsgemeinschaft (Grant SI 738/1-1) (H.R.S.), and the European Commission Improving Human Potential program (contract number HPRI-CT-1999-00025) (V.R.).

Correspondence should be addressed to Dr. Lucy Lee, Wellcome Department of Imaging Neuroscience, 12 Queen Square, London, WC1N 3BG UK. E-mail: llee@fil.ion.ucl.ac.uk.

Copyright $\odot 2003$ Society for Neuroscience $\quad$ 0270-6474/03/235308-11\$15.00/0
}

(1993), it has been shown that $1 \mathrm{~Hz}$ rTMS decreases facilitatory interactions between intracortical circuits at the site of stimulation (Romero et al., 2002).

Remote effects of $1 \mathrm{~Hz}$ rTMS to primary sensorimotor hand area include decreased corticospinal excitability of the contralateral primary motor cortex (Wassermann et al., 1998) and reduced responsiveness of ipsilateral somatosensory cortex to peripheral stimulation (Enomoto et al., 2001). When delivered to the premotor cortex, $1 \mathrm{~Hz}$ rTMS reduces the excitability of intrahemispheric connections between dorsal premotor cortex and ipsilateral motor hand area (Gerschlager et al., 2001; Munchau et al., 2002).

Although $1 \mathrm{~Hz}$ rTMS modulates many aspects of motor cortex excitability, no impairment of manual motor control has been demonstrated convincingly during simple motor tasks, e.g., paced fist clench (Pascual Leone et al., 1998), finger tapping (Wassermann et al., 1996; Chen et al., 1997), peak force, and acceleration during finger pinch (Muellbacher et al., 2000). This suggests that the motor system is able to compensate, to some extent, for temporary alterations in excitability. Potentially, this makes rTMS a useful tool for studying plastic reorganization in the healthy motor system and may provide insights into adaptive mechanisms after injury such as ischemic stroke.

This study used functional imaging and analyses of effective connectivity to investigate neural correlates of three rTMSrelated effects on motor cortex activity: (1) changes in neural activity at the site of stimulation and at remote cortical and sub- 
cortical sites associated with 30 min subthreshold stimulation; (2) reduced responsiveness of the stimulated site to input from other cortical areas; and (3) the ability of the motor system to compensate for rTMS-induced alterations in cortical excitability. Previous functional imaging experiments using positron emission tomography (PET) (Fox et al., 1997; Siebner et al., 2001) and functional magnetic resonance imaging (fMRI) (Bohning et al., 2000) have investigated local and remote effects of $1 \mathrm{~Hz}$ rTMS on cortical activity. The present study extends this work by exploring movement-related responses in addition to resting activity.

\section{Materials and Methods}

Subjects. Eight healthy, right-handed volunteers (one female) aged between 20 and 68 years (mean age: 37 years), with no history of neurological disorder or head injury, were recruited from the database of volunteers at the Functional Imaging Laboratory, Institute of Neurology, University College London, UK. Written informed consent was obtained from all participants. The study was approved by the joint ethics committee for the National Hospital for Neurology and Neurosurgery and the Institute of Neurology. The administration of radioactivity was covered under the Motor Studies License from the Administration of Radioactive Substances Advisory Committee held at the Functional Imaging Laboratory [RPC528-890 (14364)].

Study design. The study had a $2 \times 2$ factorial design, with two levels per factor: "intervention" (real-rTMS vs sham-rTMS) and "task" (movement vs baseline). Figure 1 illustrates the study design. Real- and shamrTMS were given on 2 separate days, at least 1 week apart. The order of intervention was counterbalanced across subjects. The effects of rTMS were assessed by consecutive PET measurements of regional cerebral blood flow (rCBF) during the first hour after rTMS. Within each scanning session the baseline and movement tasks were alternated. The order of tasks was kept constant within a subject between sessions but was counterbalanced across subjects.

Repetitive transcranial magnetic stimulation. In each rTMS session, 1800 biphasic stimuli were given over the left primary motor hand area using a MagStim rapid stimulator connected to four booster modules (MagStim Company, Whitland, Wales, UK). All subjects received two 15 min trains of $1 \mathrm{~Hz}$ rTMS separated by an intertrain interval of $1 \mathrm{~min}$, delivered outside the PET scanner. Stimulation intensity was set to $90 \%$ of resting motor threshold (RMT) of the right, first dorsal interosseus (FDI) muscle. A standard figure-of-eight shaped coil (double $70 \mathrm{~mm}$; coil type P/N 9925, MagStim Company) was used for real-rTMS. For sham-rTMS a specially designed sham coil that induced no magnetic field but provided a comparable acoustic stimulus was used (MagStim Company). The coil was positioned with the handle at $45^{\circ}$ to the sagittal plane. The current flow of the initial rising phase of the biphasic pulse in
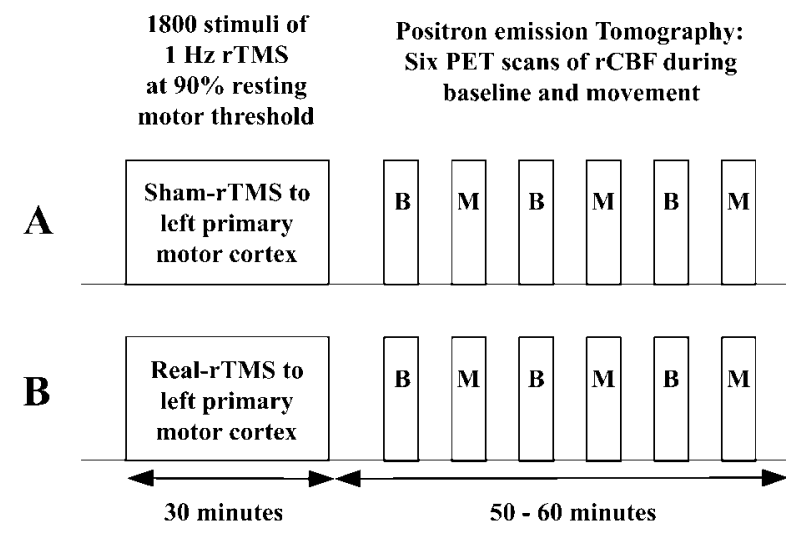

Figure 1. Experimental design. Subjects received $1 \mathrm{~Hz}$ real- or sham-rTMS on separate days. Changes in regional cerebral blood flow were mapped using PET. Six sequential $\mathrm{H}_{2}{ }^{15} \mathrm{OPET}$ scans were acquired at baseline (B) or during the freely selected movement task (M) in alternation during the hour after the end of rTMS. The order of intervention (real-rTMS vs sham-rTMS) and experimental conditions were counterbalanced across subjects. the TMS coil induced a current flowing from posterior to anterior in the underlying motor cortex.

The site of rTMS stimulation was located at the "motor hot spot," defined functionally as the point of maximum evoked motor response in the relaxed right FDI muscle. The resting motor threshold was defined as the lowest stimulus intensity that elicited at least five twitches in 10 consecutive stimuli given over the motor hot spot. The FDI muscle was used to define the motor threshold because TMS-evoked twitches are clearly visible, and it has a threshold similar to other intrinsic hand muscles. This ensured that the intensity used for rTMS was below movement threshold for all the hand muscles. The use of subthreshold intensity (1) avoided muscle twitches during rTMS that could modulate central processing via sensory afferents and (2) reduced the spread of the stimulation away from the targeted site. An intensity of 90\% RMT was chosen because this is above the threshold for activating corticospinal output projections. The latter is usually assessed by measuring active motor threshold (the intensity needed to produce electromyograph activation in precontracting muscles) and is equivalent to $\sim 80 \%$ RMT. We could therefore be certain that the rTMS pulses produced synaptic activation in at least some of the projection sites of $\mathrm{M}_{1}$.

Motor task. Subjects underwent six sequential $\mathrm{H}_{2}{ }^{15} \mathrm{O}$ PET scans on each of the 2 separate days. All scans were acquired during the first hour after $30 \mathrm{~min}$ of $1 \mathrm{~Hz}$ rTMS to the motor cortex. Normalized rCBFdependent uptake (referred to hereafter as rCBF) was used as an index of regional synaptic activity during two experimental conditions: baseline (referred to as condition " $\mathrm{B}$ ") and random selection of finger movements (referred to as condition " $M$ "). Three PET scans were acquired for each of the experimental conditions in an alternating order (B-M-B-M-B-M or M-B-M-B-M-B). Subjects were required to keep their eyes open and fixate a cross on the center of a screen located $0.7 \mathrm{~m}$ in front of their face. A pacing tone sounded every $2 \mathrm{sec}$ during both conditions. During the movement task, subjects were required to freely select and execute brisk flexion movements with the index, middle, ring, or little finger of their right hand. They were asked to make a fresh choice on each trial, regardless of previous moves, so as to produce a random sequence. The instructions emphasized that each choice should be independent of previous choices. Subjects were told to actively prepare the forthcoming movement and execute the movement as soon as they heard the pacing tone. To ensure a stable level of task performance, the random selection task started $\sim 20 \mathrm{sec}$ before the onset of the PET scan and lasted for the entire $90 \mathrm{sec}$ period of data acquisition. During the baseline condition, subjects were instructed to watch the fixation point and listen to the tones. Subjects practiced this to avoid learning effects during scanning.

Subjects responses were made on four buttons, set under their fingertips on a molded wrist splint. All responses were recorded by computer (Apple Macintosh 7300) using COGENT Cognitive Interface Software (Wellcome Department of Imaging Neuroscience, London, UK). The data were subsequently analyzed using Matlab 6.0 (Mathworks, Sherborn, MA) and SPSS 8.0 (SPSS Inc., Chicago, IL).

Behavioral assessment. In addition to the random selection task during scanning, subjects performed two finger-tapping tasks with their right hand after the first, third, and fifth PET scan. These tasks served as additional control conditions to detect potential behavioral effects of rTMS. In the "simple tapping task," subjects tapped their right index finger as many times as possible during a $10 \mathrm{sec}$ interval. In the "sequential tapping task," subjects were asked to repeat an ascending sequence (index, middle, ring, little finger) as quickly as possible for $10 \mathrm{sec}$. Having familiarized the subjects with the tasks outside the PET scanner, each of the tasks was performed twice in the PET scanner before rTMS on both scanning sessions. This was done to reduce learning effects during sequential PET scans.

From each task, the mean interval between responses and the mean duration of button presses were calculated, as indices of motor performance. These values were entered into a paired-samples $t$ test to look for differences after real-rTMS compared with sham-rTMS. The free selection movement task during scanning was paced; therefore only the mean duration of button presses was considered as a kinematic variable of interest. Simpson's equitability index (Simpson, 1949) was calculated for sequential response pairs and taken as a measure of the randomness of 


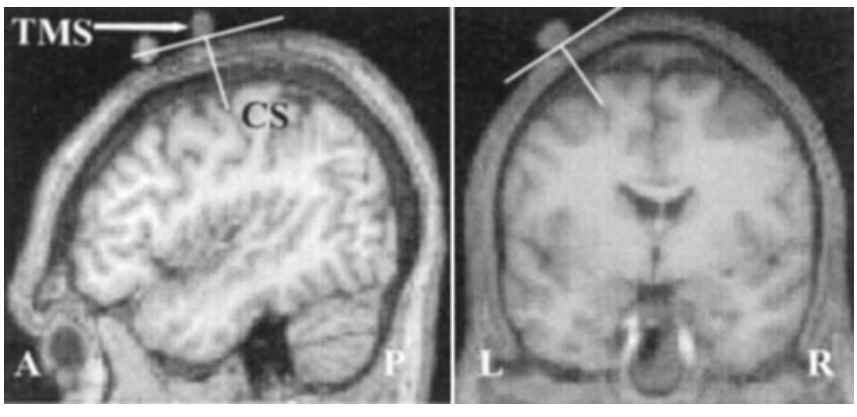

Figure 2. Position and orientation of TMS coil (TMS) relative to the central sulcus (CS) shown in one subject. N.B.: Capsules marking the position of the premotor cortex, visible in the sagittal scans, anterior to TMS, are part of a different experiment.

the sequence. This index varies between 0 and 1 . A value of 1 indicates that, over a series of responses, any given response was equally likely to be followed by any other response. Data from the three repetitions of this task, during each scan, were analyzed to provide two values of randomness for each subject: one after sham-rTMS and one after real-rTMS. These values were entered into a paired-samples $t$ test to look for rTMSrelated differences. Significance was set at $p<0.05$. In addition to the paired $t$ tests described above, each of the behavioral measurements was entered into a two-way repeated measures ANOVA, with "intervention" (sham vs real rTMS) and time (before rTMS vs three time points after rTMS) as factors.

PET data acquisition. PET was performed using a CTI ECAT HR+ scanner (CTI, Knoxville, TN) in three-dimensional mode with interdetector collimating septa removed. The axial field of view was $155 \mathrm{~mm}$, providing whole-brain coverage including cerebellum. The subjects lay supine in the scanner. A padded helmet with a chinstrap, fixed to the headrest, reduced head movement. A TV monitor was adjusted to give subjects an unrestricted view of the instructions and fixation point.

Regional cerebral blood flow was assessed using $\mathrm{H}_{2}{ }^{15} \mathrm{O}$. Six to $10 \mathrm{mCi}$ (mean $8.9 \mathrm{mCi}$ ) were delivered intravenously over $20 \mathrm{sec}$ to the left arm. Image acquisition began $5 \mathrm{sec}$ before the rising phase of the count curve, $\sim 25-35 \mathrm{sec}$ after injection, and continued for $90 \mathrm{sec}$. Correction for tissue and helmet attenuation was made using a transmission scan from ${ }^{68} \mathrm{Ga} /{ }^{68} \mathrm{Ge}$ sources at the start of each scanning session. The interscan interval was $\sim 8 \mathrm{~min}$. Corrected data were reconstructed by threedimensional filtered back-projection (Hanning filter, cutoff frequency 0.5 cycles per pixel) and scatter correction. Sixty-three transverse planes were obtained with a $128 \times 128$ pixel image matrix, with a pixel size of $2.4 \times 2.1 \times 2.1 \mathrm{~mm}$ and a resolution of $\sim 6 \mathrm{~mm}$ at full-width half-maximum.

In all subjects, the position of the center of the eight-shaped coil was marked on the skull with a capsule containing cod liver oil. Anatomic structural images were acquired before rTMS stimulation, with the TMS surface markers in place, using a VISION MR scanner at 2 tesla (Siemens, Erlangen, Germany) with a T1 MPRAGE sequence (echo time $=4 \mathrm{msec}$; repetition time $=9.5 \mathrm{sec}$; inversion time $=600 \mathrm{msec}$; resolution $1 \times 1 \times$ $1.5 \mathrm{~mm} ; 108$ axial slices). This structural image also excluded asymptomatic structural brain abnormalities. In all subjects the cod liver oil capsule marking the motor hot spot was clearly visible, located over the central sulcus. Examples of the TMS coil placement scans for one subject can be seen in Fig. 2.

Image analysis. All image analysis was performed using Statistical Parametric Mapping software, SPM99 (Wellcome Department of Imaging Neuroscience, University College London, UK; http://www.fil.ion. ucl.ac.uk/spm). For each subject, images were realigned to the first image by rigid body correction for head movements between scans and change of position between sessions (Friston et al., 1995a). All images were then normalized to a standardized anatomic space (Talairach and Tournoux, 1988) by matching to a standardized PET template using linear and nonlinear spatial transformations (Friston et al., 1995a). Each image was smoothed with an isotropic Gaussian kernel of $12 \mathrm{~mm}$ full-width at half-maximum to accommodate intersubject differences in anatomy and
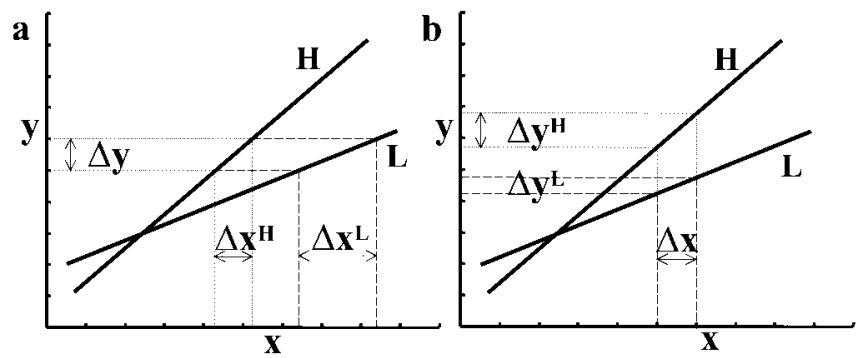

Figure 3. Interpretation of PPI analyses. This schematic shows that two mathematically equivalent but biologically complementary hypotheses can be used to motivate the same PPI. In both graphs, $x$ represents activity in an index area subtending the physiological variance in the PPI analysis. Conditions $H$ and L represent some psychological or experimental manipulation. In $a$ during $\mathrm{H}$, a unit increase in activity in area $\mathrm{y}(\Delta \mathrm{y})$ is associated with a small increase in activity in area $\mathrm{x}: \Delta \mathrm{x}^{\mathrm{H}}$ (dotted line). During $\mathrm{L}, \Delta \mathrm{y}$ is associated with a larger increase in activity in area $\mathrm{x}: \Delta \mathrm{x}^{\mathrm{L}}$ (dashed line). Consequently, this is the change that one would predict if we thought area $\mathrm{x}$ was less responsive to $\Delta y$ during $\mathrm{H}$. In $b$ during $\mathrm{H}$, a unit increase in activity in area $\mathrm{x}(\Delta \mathrm{x})$ is associated with a large increase in activity in area $\mathrm{y}: \Delta \mathrm{y}^{\mathrm{H}}$ (dotted line). During $\mathrm{L}, \Delta \mathrm{x}$ is associated with a smaller change in activity in area $y: \Delta y^{\mathrm{L}}$ (dashed line). In short, exactly the same PPI would be predicted if we thought that area y was more responsive to $\Delta x$ during $\mathrm{H}$.

enable the application of Gaussian field corrections during inference (Friston et al., 1995a).

The primary analysis used a general linear model that included 12 covariates modeling the task (movement selection vs baseline) separately for each consecutive scan pair, first to third, under each condition of treatment (real-rTMS vs sham-rTMS). The effect of global differences in cerebral blood flow among scans was removed by treating global activity as a confound and scaling to a nominal grand mean of $50 \mathrm{ml} / 100 \mathrm{gm}$ per minute (Friston et al., 1995b). This statistical model enabled characterization of the main effects of rTMS (real-rTMS vs sham-rTMS) and task (movement vs baseline) and for movement-by-rTMS interactions, as well as modeling the effects of time and time-by-condition-by-task interactions. For the main effect of movement, the reporting criterion was set at $p<0.05$, corrected for multiple nonindependent comparisons over the whole brain. Results for the main effects of rTMS and rTMS by movement interactions are reported at $p<0.05$, using a small volume correction (16 mm radius sphere centered on the maxima of the main effect of movement).

Predicted changes in effective connectivity within the motor network were assessed using the psychophysiological interaction (PPI) method described by Friston et al. (1997). PPI refers to the interaction between physiological activity in the brain and a psychological or experimental context. In this study, context was defined by the level of rTMS (real vs sham). PPI analyses aim to explain regionally specific responses in terms of the interaction between the psychological variable and the activity in a specified index area. Although the context (real- vs sham-rTMS) enters the model explicitly, the effect of task (move vs baseline) usually enters vicariously as the principal cause of variance in the index region. The analysis is constructed to test for differences in the regression slope of activity in all areas, on the activity in the index area, under the two stimulation conditions. These regression slopes are a metric of the coupling between the two areas. The PPI therefore identifies areas in which the degree of coupling with the index region is modulated significantly by rTMS. The presence of a significant change in coupling between the index region and other brain areas can be interpreted in two distinct ways: either as a change in the influence of the index area on other brain regions or as a change in the responsiveness of the index area to inputs from other brain regions. These complementary interpretations of PPIs are illustrated in Figure 3. Note that a significant PPI cannot be used to disambiguate these interpretations post hoc. A PPI is used to test an $a$ priori hypothesis about decreased responsiveness or increased influence of the index region. We will use examples of both below.

The first PPI was used to test the hypothesis that rTMS alters the responsiveness of the site of stimulation to activity in other motor areas. This hypothesis was motivated by previous work demonstrating that 
Table 1. Mean group data $( \pm S D)$ of kinematic measures (duration of press and interval between presses for the index tapping and sequential tapping tasks, plus duration of press for the free selection task)

\begin{tabular}{|c|c|c|c|c|}
\hline & Post-sham & Post-TMS & $t$ & $p$ \\
\hline \multicolumn{5}{|l|}{ Index tapping $(n=8)$} \\
\hline Duration (msec) & $\begin{array}{c}111.73 \\
( \pm 21.296)\end{array}$ & $\begin{array}{c}119.79 \\
( \pm 22.36)\end{array}$ & $\begin{array}{l}-1.49 \\
d f=7\end{array}$ & 0.18 \\
\hline Interval (msec) & $\begin{array}{c}198.16 \\
( \pm 16.19)\end{array}$ & $\begin{array}{c}199.48 \\
( \pm 18.39)\end{array}$ & $\begin{array}{l}-0.38 \\
d f=7\end{array}$ & 0.71 \\
\hline \multicolumn{5}{|l|}{ Sequential tapping $(n=7)$} \\
\hline Duration (msec) & $\begin{array}{c}242.22 \\
( \pm 180.98)\end{array}$ & $\begin{array}{c}244.61 \\
( \pm 154.68)\end{array}$ & $\begin{array}{l}-0.12 \\
d f=6\end{array}$ & 0.91 \\
\hline Interval (msec) & $\begin{array}{c}310.68 \\
( \pm 80.53)\end{array}$ & $\begin{array}{c}324.26 \\
( \pm 67.6)\end{array}$ & $\begin{array}{l}-0.73 \\
d f=6\end{array}$ & 0.5 \\
\hline \multicolumn{5}{|l|}{ Random selection task $(n=8)$} \\
\hline Duration (msec) & $\begin{array}{c}234.89 \\
( \pm 50.89)\end{array}$ & $\begin{array}{c}224.5 \\
( \pm 57.87)\end{array}$ & $\begin{array}{c}0.83 \\
d f=7\end{array}$ & 0.43 \\
\hline Simpson's equitability index & $\begin{array}{c}0.77 \\
( \pm 0.13)\end{array}$ & $\begin{array}{c}0.76 \\
( \pm 0.13)\end{array}$ & $\begin{array}{c}0.59 \\
d f=7\end{array}$ & 0.57 \\
\hline
\end{tabular}

For the random selection task Simpson's equitability index, mean ( $\pm S D$ ), is a measure of randomness. The equitability index ranges from 0 (non-random) to 1 (fully random).

rTMS reduces the sensitivity of primary motor cortex to peripheral and exogenous inputs. The analysis was specified to identify cortical areas with an attenuated influence on the stimulation site after rTMS. The physiological variable here comprised the first eigenvariate of the $\mathrm{rCBF}$ signal from a sphere (radius $8 \mathrm{~mm}$ ) centered on the voxel in primary motor showing the greatest TMS-induced increases (see Table 3). The eigenvector was adjusted to remove subject-specific effects. This ensured that the analysis was sensitive to within-subject variation in activity, and the results do not reflect between-subject differences. A PPI term (a regressor representing the interaction between physiological activity and experimental context) was obtained by multiplying the physiological variable by the TMS-specific effect. Having included the effects of the physiological component (activity in the index region) and the psychological component (real-rTMS vs sham-rTMS) in the same model, SPM was used to test for the PPI (an example of a design matrix is displayed in Fig. 7). The resulting SPM $\{t\}$ reflects the significance of the PPI. To quantify the effects of rTMS on the motor network identified by the primary analysis, regression slopes were plotted for areas where $p<0.05$ (corrected for a $16 \mathrm{~mm}$ radius sphere centered on the maxima of the main effect of movement). In this PPI, a significant increase in the regression slope was predicted by a reduction in the response of the index area (the site of rTMS) to putative input from other brain areas (Fig. $3 a$ ). This is because the slope represents the ratio of changes in the significant area to changes at the rTMS site. Therefore, positive interactions identify regions where movement-related activity is associated with a smaller response at the site of rTMS after stimulation.

The second analysis of effective connectivity was designed to test the hypothesis that after rTMS there are compensatory increases in the influence of components of the motor network involved in the performance of the motor task on nonstimulated regions. Three areas ipsilateral to the site of stimulation were chosen on the basis of the known anatomical connections with the site of stimulation and the areas involved in action preparation and execution: left primary sensorimotor hand area, left dorsal premotor cortex, and left supplementary motor area (SMA). Three separate PPI analyses were performed, one for each area. In each case the physiological variable was the first eigenvariate of the $\mathrm{rCBF}$ signal from a region of interest (sphere $8 \mathrm{~mm}$ radius) identified by the main effect of movement. The covariate of interest was constructed and tested using SPM as described above. In these three PPI analyses, a significant increase in the regression slope between two areas (a positive interaction) can be interpreted as rTMS-induced increases in movement-related influence of the index area on the regions identified (Fig. $3 b)$.

\section{Results}

Subjects did not report any adverse side effects during the course of the study, nor were any motor responses evoked during the 30 min of rTMS. Mean resting motor threshold was $62 \%$, ranging from 46 to $72 \%$ of maximum output of the MagStim rapid stimulator.

\section{Behavioral data}

We did not find a significant effect of $1 \mathrm{~Hz}$ rTMS on the rate and duration of finger presses during simple and sequential finger tapping. This is in agreement with previous work investigating the effects of rTMS on simple motor behavior (Wassermann et al., 1996; Chen et al., 1997; Pascual Leone et al., 1998; Muellbacher et al., 2000; Rossi et al., 2000). All eight subjects performed the random movement selection task during scanning without difficulty. Likewise there were no difficulties for the simple index tapping performed between scans. However, during the sequential tapping task between scans, one subject failed to make any presses with the ring or little fingers and therefore was excluded from the analysis of these data. Table 1 shows the averaged group values (mean $\pm \mathrm{SD}$ ) of the variables used to assess behavior after $30 \mathrm{~min}$ of $1 \mathrm{~Hz}$ rTMS, in terms of motor performance and free selection of movement. Statistical analysis of these behavioral data excluded any behavioral confound in the neurophysiological analyses in the sense that there were no effects of rTMS on any performance index.

For the simple tapping task, there was no effect of rTMS on the duration of button presses or on the interval between button presses. For the sequential tapping task there was no effect of rTMS on duration of button presses or on the interval between presses. For freely selected movements, rTMS had no effect on the randomness of responses measured by Simpson's equitability index or on the duration of button presses. A repeated measures ANOVA used to test for time by condition interactions also failed to detect any significant effect (results not shown).

\section{Imaging data}

Conventional analyses were used to investigate the distributed changes in synaptic activity associated with movement, prolonged submotor threshold $1 \mathrm{~Hz}$ rTMS, and the interaction between these effects. Analyses of effective connectivity addressed two distinct issues: (1) identification of cortical areas with an influence on the stimulation site that was attenuated by rTMS, and (2) areas that were more sensitive to motor, premotor, and SMA inputs after rTMS has been used to alter the excitability of primary motor cortex. 

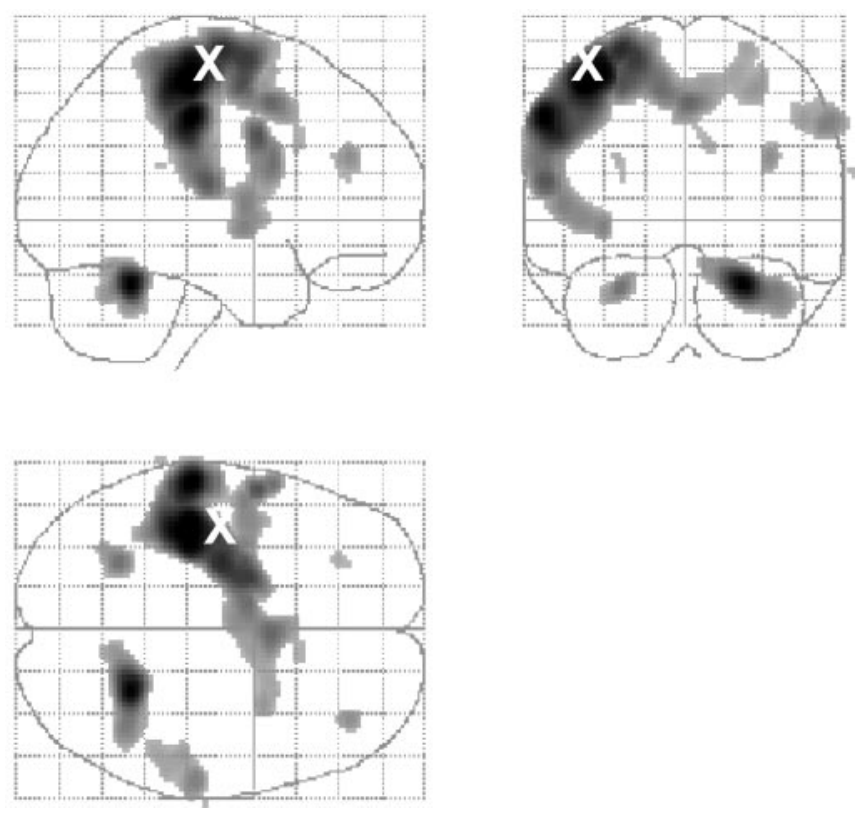

Figure 4. Regional activations during freely selected finger movements (main effect of movement). Results are displayed as statistical parametric maps on sagittal, coronal, and transverse projections in stereotactic space. The grayscale areas indicate all significant voxels showing a movement-related activation at $p<0.05$ (corrected for multiple comparisons). The $X$ indicates the site of rTMS stimulation.

\section{Movement-related activations (main effect of task)}

The movement task activated a number of motor areas compatible with freely selected right-hand movements (Fig. 4, Table 2) (reported at $p<0.05$ corrected for multiple comparisons). These included the left primary sensorimotor cortex, extending to the left dorsal premotor cortex and left SMA. Additional activations were also seen in the right dorsal premotor cortex, right SMA, right rostral motor cingulate cortex, and left ventral premotor cortex. There were also bilateral activations in the lateral prefrontal cortex and the cerebellum.

\section{Changes in rCBF induced by rTMS (main effect of rTMS)}

Compared with sham, real-rTMS caused widespread increases and decreases in rCBF throughout the brain (Table 3). There were no significant main effects of time, or time-by-condition interactions (intra-session effects), indicating that rTMS induced sustained changes in $\mathrm{rCBF}$ for at least $1 \mathrm{hr}$.

The left primary motor hand area, which was directly targeted by rTMS, showed a sustained increase in rCBF after real-rTMS (averaged over move and baseline conditions) (Fig. 5). rTMS also induced bilateral increases in $\mathrm{rCBF}$ in the dorsal premotor cortices (Fig. 5) and cerebellum. Other motor areas showing lasting increases included left caudal SMA, left basal ganglia, and bilateral foci in the inferior parietal lobule. There was also greater activity in the right prefrontal area and bilateral parietal regions.

There were no decreases in rCBF at or near the site of stimulation (Table 3); however, we found significant decreases in the right cingulate motor cortex and the left ventral premotor area. Additional rCBF decreases were located in frontal operculum, superior temporal gyrus, right cerebellum, and lateral prefrontal cortices.

\section{rTMS-induced changes in task-related activation (movement-by-rTMS interaction)}

Increases in task-specific activation (movement vs baseline) after real-rTMS (vs sham-rTMS) were found in two areas. These were left primary sensorimotor cortex $(x=-30, y=-24, z=48$; $Z$ score $=3.6 ; p=0.028)$ and right dorsal premotor cortex $(x=30$, $y=4, z=54 ; Z$ score $=3.55 ; p=0.033$ ). Figure 6 shows the anatomical location of these activations. rTMS caused no taskspecific decreases in activation.

Table 2. Main effect of movement

\begin{tabular}{|c|c|c|c|c|c|c|}
\hline \multirow[b]{2}{*}{ Brain region } & & \multicolumn{3}{|c|}{ MNI Coordinates of peak activation } & \multirow{2}{*}{$\begin{array}{l}Z \text { value of peak } \\
\text { activation }\end{array}$} & \multirow{2}{*}{$\begin{array}{l}p \text { value whole } \\
\text { volume corrected }\end{array}$} \\
\hline & & $x$ & $y$ & $Z$ & & \\
\hline Sensorimotor & Left & -42 & -26 & 56 & $>8$ & $<0.001$ \\
\hline Primary sensory & Left & -58 & -26 & 42 & 7.81 & $<0.001$ \\
\hline \multirow[t]{3}{*}{ Premotor (PMd) } & Left & -20 & -4 & 64 & 6.85 & $<0.001$ \\
\hline & Left & -26 & -14 & 68 & 7.12 & $<0.001$ \\
\hline & Right & 30 & 4 & 52 & 5.25 & 0.004 \\
\hline \multirow[t]{3}{*}{ Premotor (PMv) } & Left & -58 & 8 & 24 & 5.96 & $<0.001$ \\
\hline & Left & -56 & 2 & 34 & 6.47 & $<0.001$ \\
\hline & Left & -52 & -4 & 6 & 5.64 & $<0.001$ \\
\hline \multirow[t]{3}{*}{ SMA } & Left & -10 & -2 & 52 & 6.09 & $<0.001$ \\
\hline & Left & -12 & -4 & 56 & 5.98 & $<0.001$ \\
\hline & Right & 8 & 0 & 54 & 5.17 & 0.005 \\
\hline \multirow[t]{2}{*}{ Cingulate motor (rostral) } & Right & 10 & 18 & 30 & 4.87 & 0.002 \\
\hline & Right & 2 & 8 & 48 & 6.11 & $<0.001$ \\
\hline \multirow[t]{2}{*}{ Cerebellum } & Left & -26 & -56 & -26 & 5.91 & $<0.001$ \\
\hline & Right & 24 & -52 & -26 & 7.69 & $<0.001$ \\
\hline \multirow[t]{2}{*}{ Insula } & Left & -44 & -2 & 0 & 5.55 & 0.001 \\
\hline & Left & -34 & -4 & -2 & 5.64 & $<0.001$ \\
\hline SII (post central sulcus) & Left & -58 & -20 & 16 & 6.44 & $<0.001$ \\
\hline \multirow[t]{3}{*}{ Anterior inferior parietal/intraparietal sulcus } & Right & 60 & -24 & 40 & 5.71 & $<0.001$ \\
\hline & Right & 50 & -30 & 40 & 5.19 & 0.005 \\
\hline & Right & 52 & -38 & 40 & 5.05 & 0.009 \\
\hline \multirow[t]{4}{*}{ Prefrontal } & Left & -28 & 36 & 24 & 4.83 & 0.024 \\
\hline & Right & 36 & 40 & 26 & 5.43 & 0.001 \\
\hline & Right & 26 & 8 & 68 & 5.07 & 0.008 \\
\hline & Right & 22 & 6 & 58 & 5.05 & 0.009 \\
\hline
\end{tabular}




\begin{tabular}{|c|c|c|c|c|c|c|}
\hline \multirow{2}{*}{ Brain region } & & \multicolumn{3}{|c|}{ MNI coordinates of peak activation } & \multirow{2}{*}{$\begin{array}{l}Z \text { value of peak } \\
\text { activation }\end{array}$} & \multirow[b]{2}{*}{$p$ value SVC } \\
\hline & & $x$ & $y$ & $Z$ & & \\
\hline \multicolumn{7}{|l|}{ Increased rCBF ${ }^{a}$} \\
\hline Sensorimotor & Left & -30 & -26 & 62 & 4.02 & 0.007 \\
\hline \multirow[t]{4}{*}{ Premotor (PMd) } & Left & -14 & -16 & 68 & 4.93 & $<0.001$ \\
\hline & Left & -18 & -18 & 66 & 4.96 & $<0.001$ \\
\hline & Right & 40 & -10 & 64 & 7.06 & $<0.001$ \\
\hline & Right & 38 & -4 & 62 & 4.81 & $<0.001$ \\
\hline SMA & Left & -12 & -18 & 58 & 3.99 & 0.001 \\
\hline \multirow[t]{3}{*}{ Cerebellum } & Left & -20 & -56 & -36 & 4.51 & 0.001 \\
\hline & Left & -26 & -60 & -24 & 5.31 & $<0.001$ \\
\hline & Right & 22 & -54 & -18 & 6.67 & $<0.001$ \\
\hline Putamen & Left & -24 & -12 & 2 & 3.44 & 0.045 \\
\hline \multirow[t]{4}{*}{ Anterior inferior parietal } & Left & -66 & -30 & 38 & 3.56 & 0.032 \\
\hline & Right & 38 & -32 & 40 & 3.64 & 0.025 \\
\hline & Right & 54 & -34 & 30 & 3.81 & 0.014 \\
\hline & Right & 40 & -50 & 48 & 6.02 & $<0.001$ \\
\hline Insula & Left & -32 & -12 & -8 & 4.82 & 0.001 \\
\hline Prefrontal & Right & 20 & 10 & 70 & 3.38 & 0.054 \\
\hline \multicolumn{7}{|l|}{ Decreased rCBF ${ }^{b}$} \\
\hline Premotor (PMv) & Left & -50 & 6 & 24 & 3.6 & 0.028 \\
\hline Cingulate motor (caudal) & Right & 2 & 0 & 38 & 3.75 & 0.017 \\
\hline \multirow[t]{3}{*}{ Cingulate motor (rostral) } & Right & 6 & 20 & 48 & 5.15 & $<0.001$ \\
\hline & Right & 6 & 14 & 52 & 3.89 & 0.011 \\
\hline & Right & 10 & 14 & 52 & 3.49 & 0.039 \\
\hline Cerebellum & Right & 40 & -56 & -22 & 4.73 & $<0.001$ \\
\hline SII (post central sulcus) & Left & -44 & -24 & 36 & 3.56 & 0.031 \\
\hline \multirow[t]{2}{*}{ Operculum (44/45) } & Left & -46 & 12 & 2 & 5.21 & $<0.001$ \\
\hline & Left & -44 & 10 & -6 & 5.06 & $<0.001$ \\
\hline \multirow[t]{4}{*}{ Prefrontal } & Left & -22 & 42 & 28 & 4.23 & 0.003 \\
\hline & Right & 38 & 8 & 52 & 4.3 & 0.003 \\
\hline & Right & 34 & 12 & 50 & 3.77 & 0.017 \\
\hline & Right & 36 & 10 & 52 & 3.96 & 0.009 \\
\hline \multirow[t]{2}{*}{ Superior temporal gyrus } & Left & -58 & -8 & -2 & 6.17 & $<0.001$ \\
\hline & Left & -52 & -8 & 2 & 6.22 & $<0.001$ \\
\hline
\end{tabular}

${ }^{a}$ Maxima of regional increases in normalized rCBF after real-rTMS.

${ }^{b}$ Maxima of regional $r C B F$ decreases after $r$ TMS.

${ }^{\prime} p<0.05$ (small volume correction, using values in Table 2).

Changes in effective connectivity between the stimulated area and other motor areas (psychophysiological interactions)

Figure 7 and Table 4a show the results of the first psychophysiological interaction analysis, using the synaptic activity (as indexed by $\mathrm{rCBF}$ ) from the site of maximal rTMS-induced increase $(x=$ $-30, y=-26, z=62$ ) as the physiological variable. Table 4 a lists the coordinates of the maxima of sites shown in Figure 7, with corrected $p$ values. After rTMS, changes in activity in the left premotor $(x=-14, y=-6, z=66)$ and motor cingulate $(x=$ $-4, y=14, z=34)$ cortices were associated with a reduction in the magnitude of the response of the index area (the site of rTMS). A trend toward reduced influence was also found in a region of left sensorimotor cortex $(x=-38, y=-20, z=46)$. These PPIs are consistent with our prediction that the sensitivity of the stimulation site to input from distal areas is reduced by rTMS.

\section{Changes in effective connectivity between primary and nonprimary motor areas}

Figure 8 and Table $4 \mathrm{~b}-\mathrm{d}$ summarize the results of three psychophysiological interaction analyses looking for changes in coupling among components of the motor system activated during the movement task. When activity in the left sensorimotor hand area $(x=-42, y=-26, z=56)$ was used as the physiological component, there was a significant increase in the regression slope in the ipsilateral left sensorimotor area $(x=-38, y=-20$, $z=46$ ) after rTMS (Fig. $8 a, b$, Table $4 \mathrm{~b}$ ). The PPI analysis based on activity in the left dorsal premotor area $(x=-26, y=-14$, $z=68$ ) demonstrated that after rTMS, there was increased influence on areas in the left and right primary sensorimotor cortex (Fig. 8c,d, Table 4c). A third analysis used the activity in left SMA $(x=-12, y=-4, z=56)$ as the physiological variable. It can be seen from Table $4 \mathrm{~d}$ and Figure 8, $e$ and $f$, that rTMS increases the influence of left SMA on the left sensorimotor cortex $(x=-30$, $y=-26, z=54$ ). These results suggest that after rTMS there is a greater degree of movement-related coupling between each index site [left sensorimotor (SM1), dorsal premotor (PMd), and SMA] and activity in a cluster of inferomedial primary motor sites (Fig. 9).

\section{Discussion}

The findings of this study are discussed in two sections: (1) the neural correlates of reduced cortical excitability after $1 \mathrm{~Hz}$ rTMS and (2) mechanisms by which the brain maintains functional integrity in the context of altered cortical excitability.

\section{Neural correlates of reduced cortical excitability}

We found widespread changes in rCBF within the motor system after a period of subthreshold rTMS, including increased rCBF at the site of stimulation, that were stable for up to $1 \mathrm{hr}$ after the end of stimulation. These data extend previous $\mathrm{H}_{2}{ }^{15} \mathrm{O}$ PET studies that had described increases in neuronal activity in motor areas 


\section{Left dorsal premotor cortex (L-PMd)}
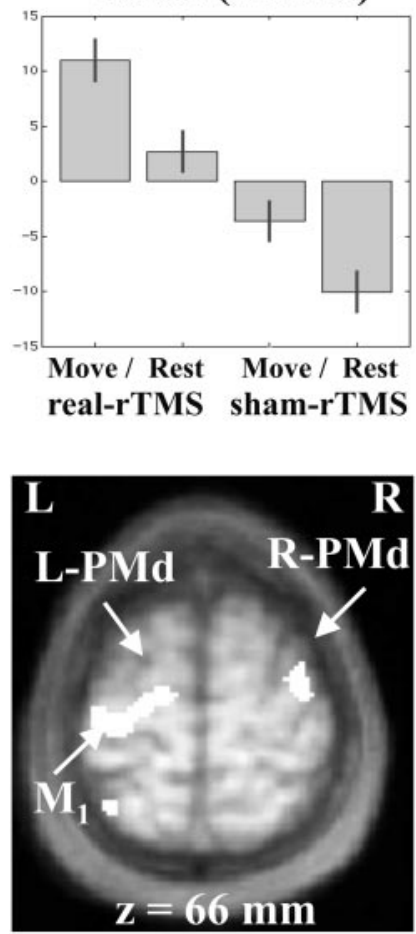

Left primary motor cortex $\left(M_{1}\right)$

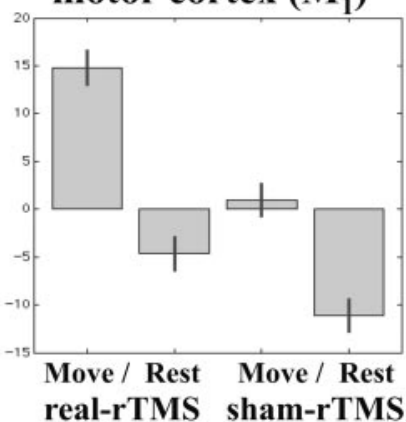

Right dorsal premotor cortex (R-PMd)

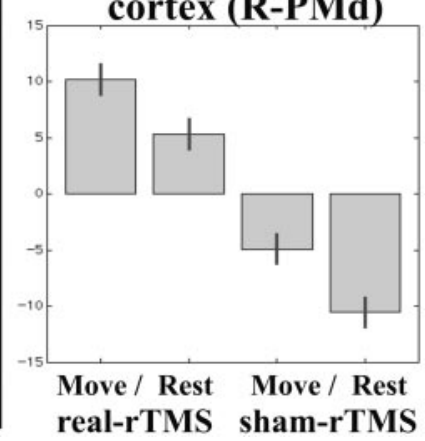

Figure 5. Regional increases in rCBF after rTMS to the left motor cortex (main effect of rTMS). Left primary motor and bilateral increases in rCBF displayed on an axial section of averaged anatomical MRI scans. Results are displayed at $p<0.001$ uncorrected, masked by main effect of movement, $p<0.001$ uncorrected (because these effects are orthogonal this corresponds to $p<0.00001$ ). Parameter estimates showing mean ( $\pm \mathrm{SE}$ ) activation during the four experimental conditions are also displayed.

during rTMS of the motor cortex (Fox et al., 1997; Siebner et al., 2001). In addition to local effects, there were statistically significant alterations in synaptic activity in areas not stimulated directly with rTMS. Changes in $\mathrm{CBB}$ at nonstimulated sites have been reported previously in studies using suprathreshold stimulation at $1 \mathrm{~Hz}$ (Fox et al., 1997). Remote effects may be mediated by corticosubcortical relays (Strafella et al., 2001) or via corticocortical connections (Wassermann et al., 1998; Siebner et al., 2000). The remote effects may represent a conditioning effect of rTMS caused by a spread of excitation via these connections. Alternatively, remote effects may reflect compensatory responses to maintain normal function of the motor system (see below).

There are two mechanisms by which rTMS can decrease cortical and corticospinal excitability (Chen et al., 1997; Maeda et al., 2000; Muellbacher et al., 2000; Fierro et al., 2001; Touge et al., 2001; Fitzgerald et al., 2002; Romero et al., 2002; Tsuji and Rothwell, 2002) while increasing $\mathrm{rCBF}$ (synaptic activity). If $1 \mathrm{~Hz}$ rTMS increases the activity of inhibitory interneurons that are metabolically demanding (Ackermann et al., 1984; Nudo and Masterton, 1986), this will increase rCBF while reducing the responsiveness of the stimulated cortical area to further stimulation. Alternatively, rTMS may reduce synaptic efficacy in the motor cortex, such that for a given excitatory input, there is less postsynaptic activity, i.e., long-term depression. Reduced efficacy of synapses terminating on pyramidal cells would account for the observed decrease in excitability as TMS effects are generated trans-synaptically (for review, see Terao and Ugawa, 2002). Compensatory excitatory presynaptic input to pyramidal cells

a) Left primary motor cortex: $x=-30, y=-24, z=48$
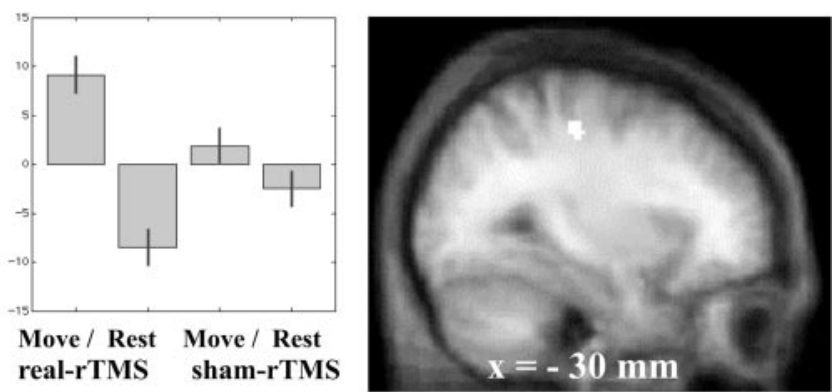

b) Right dorsal premotor cortex: $x=30, y=4, z=54$

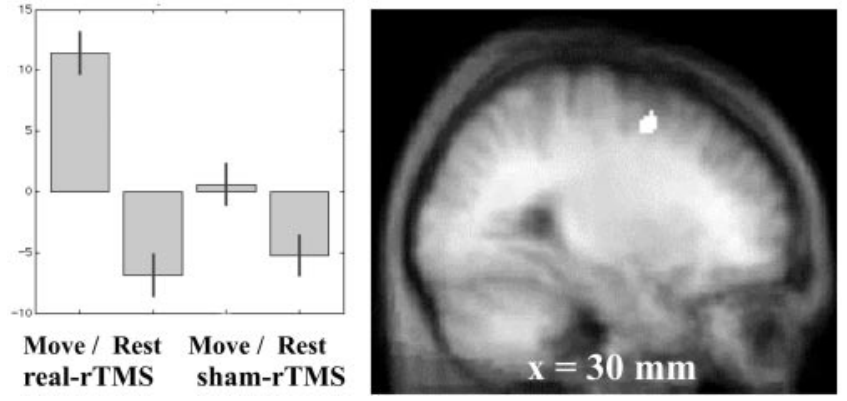

Figure 6. Areas of the brain showing differential movement-related responses after rTMS (interaction between movement and rTMS). Results are displayed on sagittal sections of averaged anatomical MRI scans at $p<0.001$ uncorrected, masked by main effect of movement as for Figure 5. Localization of activation and parameter estimates for left sensorimotor site ( $a$ ) and right premotor site $(b)$.

would result in increased synaptic activity (increased rCBF), without increased output (i.e., decreased corticospinal excitability). These compensatory changes may arise from intrinsic connections mediating cortical gain control (Abbott et al., 1997) or reflect compensatory extrinsic inputs. This explanation is in good accordance with the reduced sensitivity of primary motor cortex to somatosensory cortical activity, as shown by Tsuji and Rothwell (2002). In this study, an analysis of effective connectivity further corroborates this notion. The site of rTMS became less responsive to activity in motor areas involved in the execution of freely selected movements, specifically premotor cortex, mesial motor areas, and an inferolateral part of the primary motor cortex (Fig. 7, Table 4a).

In this study, the site of increased $\mathrm{rCBF}$ at the site of stimulation with rTMS was $13 \mathrm{~mm}$ superior and medial to the maximal activation of the left sensorimotor cortex during freely selected movement. This may be because the site of stimulation with rTMS was located by generating twitches in the FDI muscle, whereas the movement task used the full range of finger flexors and extensors. Also, the activation during movement may represent a conflation of sensory and motor effects, as compared with the purely motor site stimulated with rTMS.

\section{Maintenance of functional integrity during modulation of cortical excitability}

The right dorsal premotor cortex (contralateral to the site of stimulation) showed increased activation during freely selected finger movements of the right hand (Fig. 6). This reinforcement of movement-related activation in the contralateral premotor cortex has interesting parallels with a TMS study published recently by Johansen-Berg et al. (2002). In this study, stimulation of 

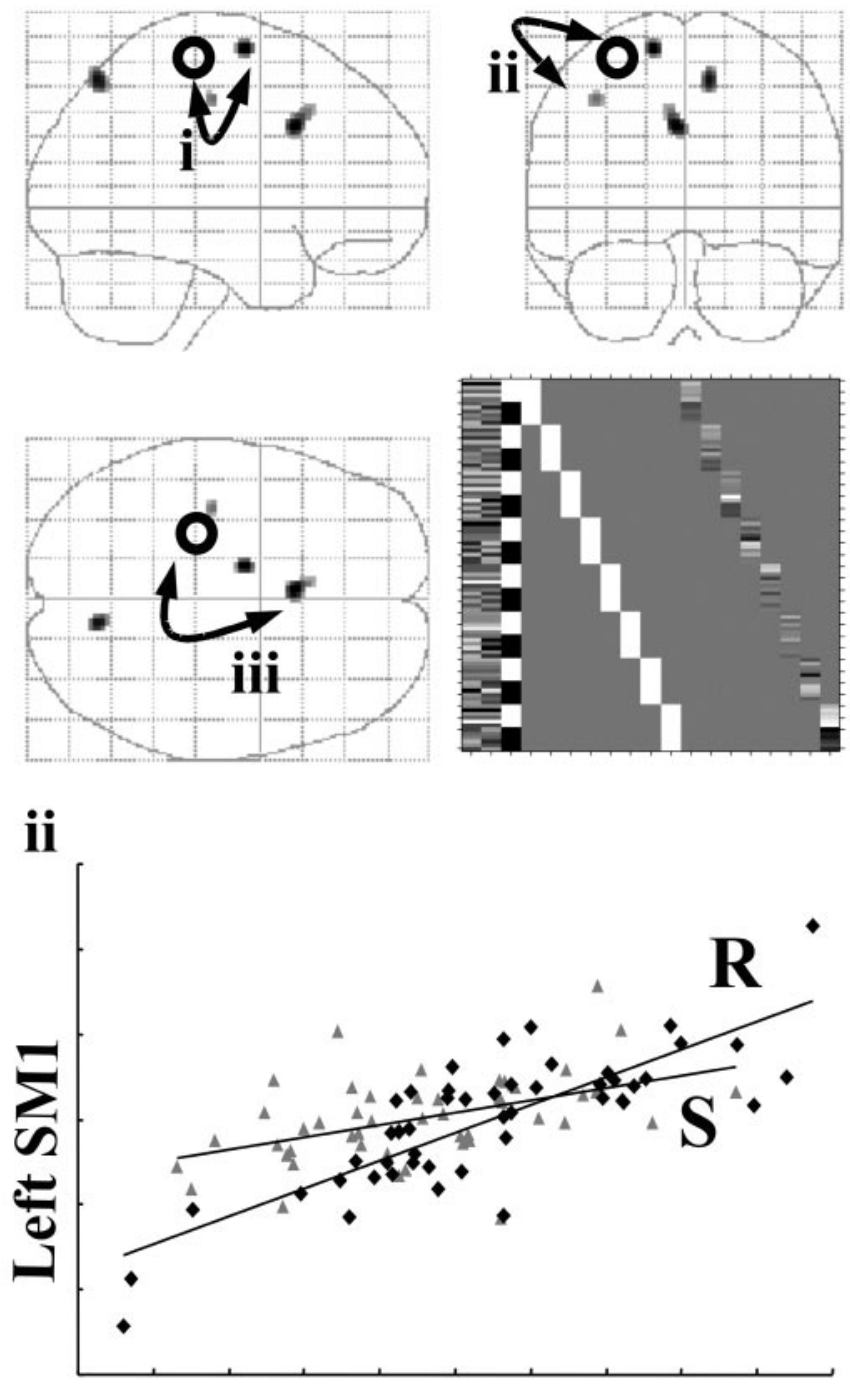

Site of rTMS (index)

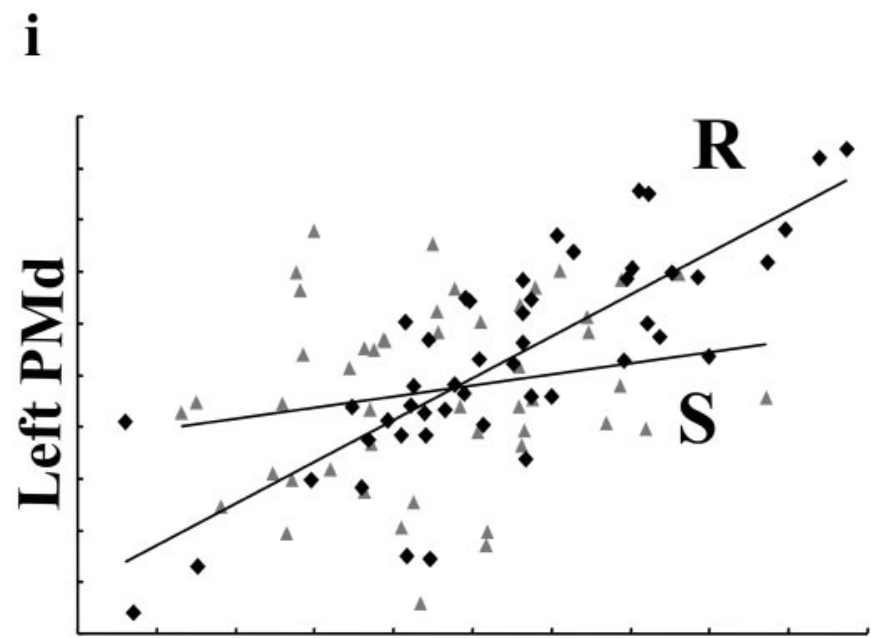

Site of rTMS (index)
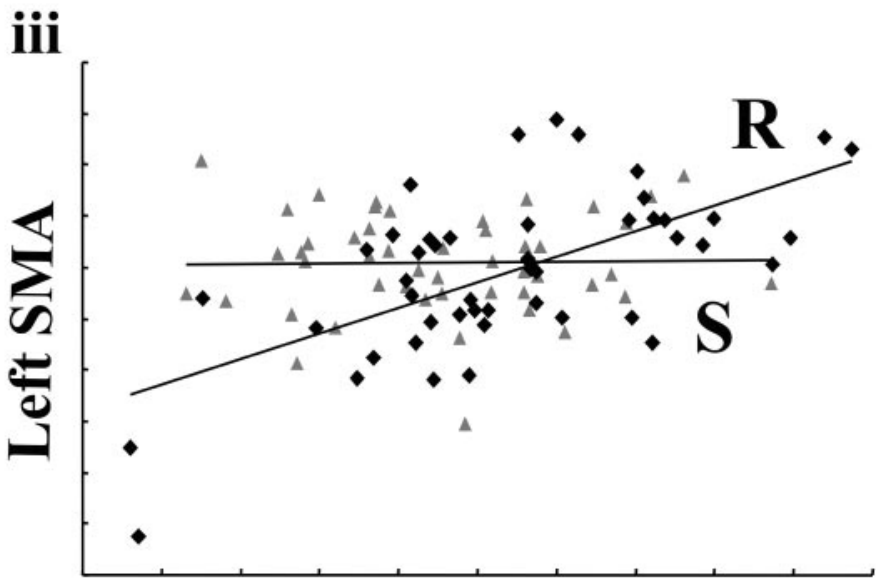

Site of rTMS (index)

Figure 7. Changes in effective connectivity (psychophysiological interaction) with the site of rTMS stimulation. Top left panel, Areas showing positive PPI with the site of rCBF increase in left sensorimotor cortex after rTMS. Results are displayed as statistical parametric maps in sagittal, coronal, and transverse projections in stereotactic space. The grayscale areas show all significant voxels at $p<0.001$, uncorrected. The black circle shows the location of the region of interest used as the physiological variate in the interaction. The design matrix is displayed alongside the statistical parametric maps. Graphical representations illustrate the psychophysiological interactions between the site of rTMS region of interest $(x=-30, y=-26, z=62)($ abscissa) and significant areas. Regression lines between the activity in the two regions have been fitted: sham-rTMS $=S$ (triangles) and real-rTMS $=R$ (diamonds). $i$, Left dorsal premotor area $(x=-14, y=-6, z=66)$. Sham-rTMS: $r^{2}=0.04, F=2.01$, gradient $=0.01$; real-rTMS: $r^{2}=0.63, F=79.40$, gradient $=0.80$. ii, Proximate left sensorimotor region $(x=-38, y=-20, z=46)$. Sham-rTMS: $r^{2}=$ $0.22, F=13.19$, gradient $=0.36$; real-rTMS: $r^{2}=0.66 F=87.37$, gradient $=0.81$. iii, Left mesial motor area $(x=-4, y=14, z=34)$. Sham-rTMS: $r^{2}=0.00, F=2.01$, gradient $=0.01$; real-rTMS: $r^{2}=0.40 F=30.17$, gradient $=0.50$.

the contralesional PMd with single-pulse TMS increased reaction times for stoke patients more than for healthy controls, and the degree of slowing correlated with impairment. The authors concluded that after stroke, increased activity in contralesional premotor cortex (Weiller et al., 1992; Seitz et al., 1998; JohansenBerg et al., 2002) during movement of the affected limb is of functional significance for motor recovery. The fact that contralesional premotor activation appears to be functionally important after stroke raises the possibility that similar mechanisms may occur after rTMS in healthy subjects, enabling unimpaired motor performance.

The second set of PPI analyses demonstrates that after rTMS activity in caudal SMA, dorsal premotor and primary motor cortices became more tightly coupled with a distinct sensorimotor cluster in the primary hand area. This cluster was close to the area in left primary sensorimotor cortex seen in the movement-byrTMS interaction (Fig. 9). It is worth noting that these sites were located inferior to the sensorimotor site that showed maximal activation during movement. This does not imply that $1 \mathrm{~Hz}$ rTMS remodels motor representations per se, but having rendered a superficial part of primary motor cortex less sensitive to inputs from premotor and mesial motor areas (Fig. 7), other regions within the primary sensorimotor cortex may become more responsive during movement. The intensity chosen for rTMS modulates more superficial portions of the primary sensorimotor cortex because the strength of stimulation attenuates with increasing vertical distance from the plane of the coil. Regions of primary sensorimotor cortex deep in the central sulcus 
Table 4. Psychophysiological interactions

\begin{tabular}{|c|c|c|c|c|c|c|}
\hline \multirow[b]{2}{*}{ Brain Region } & & \multicolumn{3}{|c|}{ MNI Coordinates of peak activation } & \multirow{2}{*}{$\begin{array}{l}Z \text { value of peak } \\
\text { activation }\end{array}$} & \multirow{2}{*}{$\begin{array}{l}p \text { value }^{e} \\
\text { SVC }\end{array}$} \\
\hline & & $x$ & $y$ & $z$ & & \\
\hline \multicolumn{7}{|c|}{ a, Main effect of rTMS increase $(-30,-26,62)$ as index region for $\mathrm{PPI}^{a}$} \\
\hline Sensorimotor & Left & -38 & -20 & 46 & 3.28 & 0.07 \\
\hline Premotor (PMd) & Left & -14 & -6 & 66 & 3.59 & 0.029 \\
\hline Cingulate motor (rostral) & Left & -4 & 14 & 34 & 3.62 & 0.026 \\
\hline \multicolumn{7}{|c|}{ b, Sensorimotor $(-42,-26,56)$ as index region for $\mathrm{PPI}^{b}$} \\
\hline \multicolumn{7}{|c|}{ c, PMd $(-26,-14,68)$ as index region for $\mathrm{PPI}^{\mathrm{C}}$} \\
\hline Sensorimotor & $\begin{array}{l}\text { Left } \\
\text { Right }\end{array}$ & $\begin{array}{r}-36 \\
44\end{array}$ & $\begin{array}{l}-22 \\
-22\end{array}$ & $\begin{array}{l}44 \\
42\end{array}$ & $\begin{array}{l}3.32 \\
4.03\end{array}$ & $\begin{array}{l}0.061 \\
0.007\end{array}$ \\
\hline \multicolumn{7}{|c|}{$\mathrm{d}, \mathrm{SMA}(-12,-4,56)$ as index region for $\mathrm{PPI}^{d}$} \\
\hline Sensorimotor & $\begin{array}{l}\text { Left } \\
\text { Left }\end{array}$ & $\begin{array}{l}-34 \\
-30\end{array}$ & $\begin{array}{l}-22 \\
-26\end{array}$ & $\begin{array}{l}48 \\
54\end{array}$ & $\begin{array}{l}3.69 \\
4.04\end{array}$ & $\begin{array}{l}0.021 \\
0.006\end{array}$ \\
\hline
\end{tabular}

${ }^{a}$ TMS site as index area: coordinates of brain regions to which the TMS site is less sensitive after rTMS.

${ }^{b-d}$ Three movement-related activations as index areas. Coordinates of brain regions showing increased coupling with left sensorimotor region (b), left dorsal premotor region (c), and left SMA after real-rTMS (d), compared with sham-rTMS. $e_{p}<0.05$ (small volume correction, using values in Table 2).

a
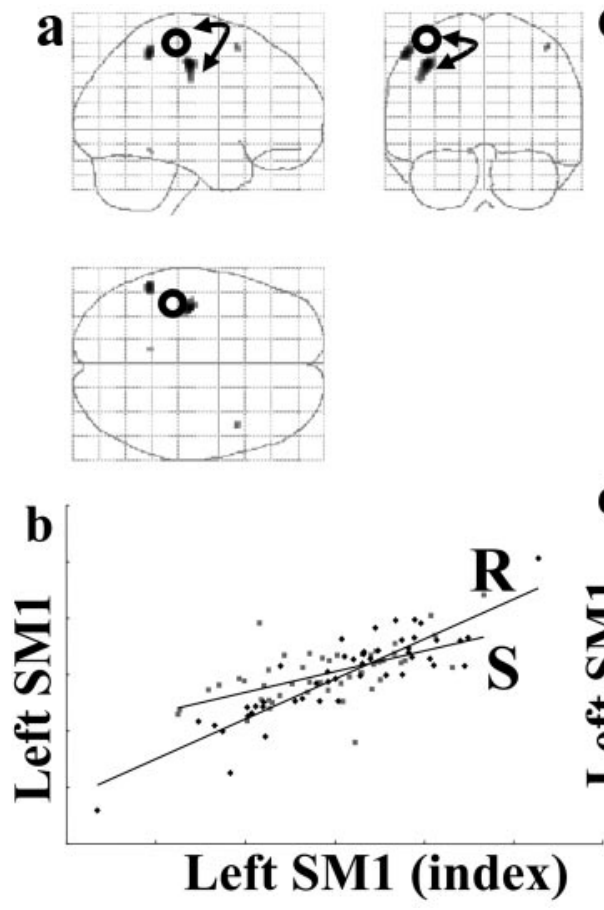

c
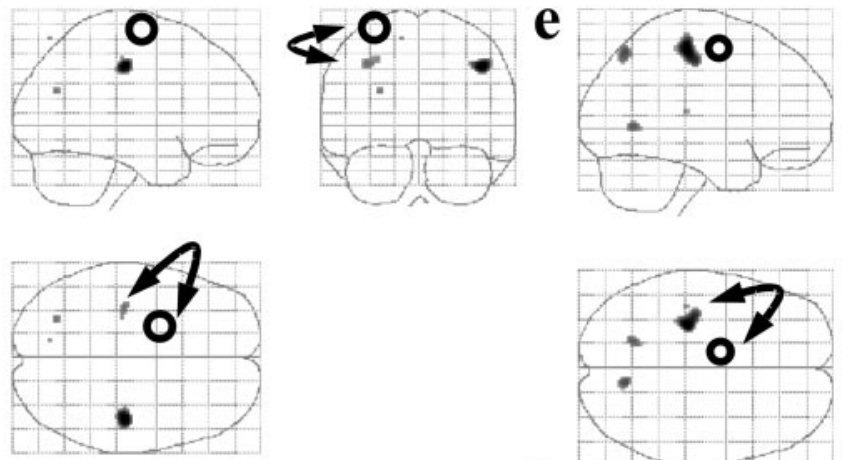

d
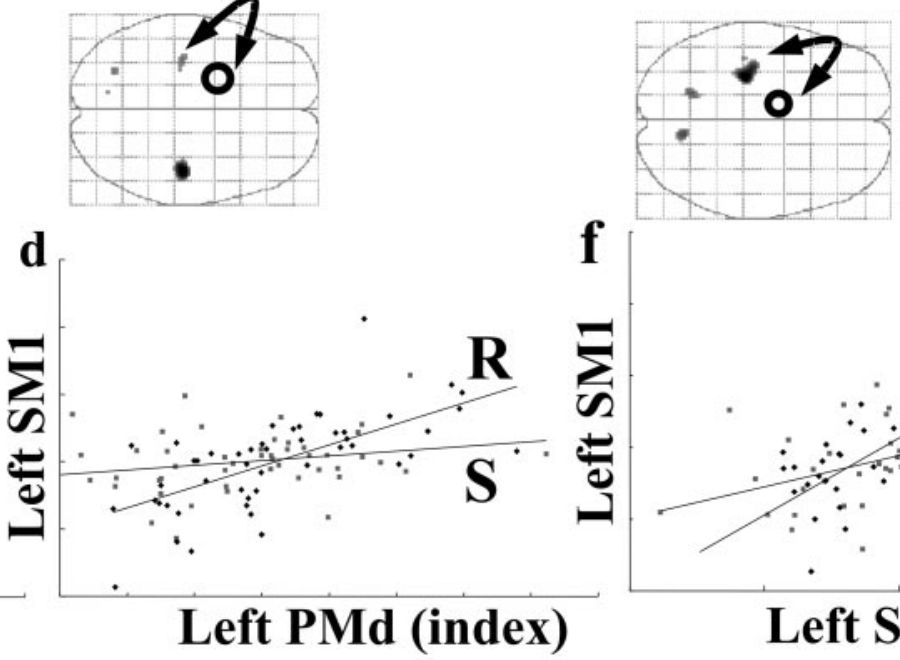

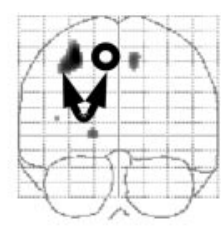

f

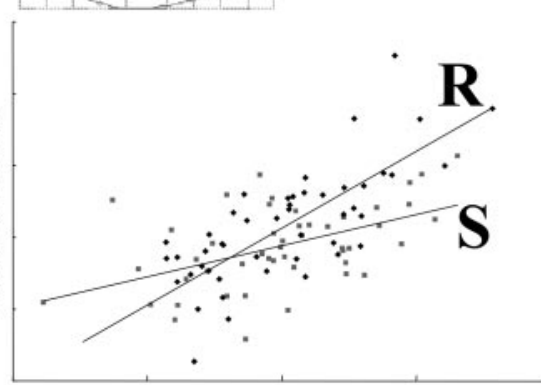

Left SMA (index)

Figure 8. Changes in effective connectivity (psychophysiological interaction) with the movement-related activations. $a$, Areas showing positive PPI with left sensorimotor region of interest $(x=$ $-42, y=-26, z=56)$ during movement-related activity after real-rTMS compared with sham-rTMS, displayed as described for Figure 7. $b$, Graphical representation illustrating the psychophysiological interactions between left sensorimotor region of interest (abscissa) and a proximate left sensorimotor region $(x=-38, y=-20, z=46)$. Regressions lines between the activity in the two regions have been fitted: sham-rTMS $=S$ (squares) $\left(r^{2}=0.36, F=25.68\right.$, gradient $\left.=0.37\right)$ and real-rTMS $=R$ (diamonds) $\left(r^{2}=0.79, F=170.87\right.$, gradient $\left.=0.71\right) . c$, Areas showing positive PPI with left premotor region of interest $(x=-26, y=-14, z=68)$, as described in Figure 7. $d$, Graphical representations illustrating the psychophysiological interactions between left premotor region of interest (abscissa) and left sensorimotor region $\left(x=-36, y=-22, z=44\right.$ ), as described for $b$. Sham-rTMS: $r^{2}=0.06, F=2.66$, gradient $=0.11 ;$ real-rTMS: $r^{2}=0.43, F=$ 34.13 , gradient $=0.78$. $e$, Areas showing positive PPI with the left SMA region of interest $(x=-12, y=-4, z=56)$, as described for Figure 7. $f$, Graphical representation illustrating the psychophysiological interactions between left SMA region of interest (abscissa) and left sensorimotor region $(x=-30, y=-26, z=54)$, as described for $b$. Sham-rTMS: $r^{2}=0.25, F=15.52$, gradient $=0.43$; real-rTMS: $r^{2}=0.61, F=71.0$, gradient $=1.07$.

would be less affected by rTMS and therefore capable of responding to input from premotor cortex and SMA during movement. Such operational remapping of motor representations would explain how the motor system compensates for rTMS-induced reductions in cortical excitability.

For this explanation to be plausible there are three requirements. First, the adult motor cortex should contain multiple motor representations and be capable of plastic changes. Second, such changes should occur at time scales similar to those seen in this experiment i.e., within $1 \mathrm{hr}$. Third, rTMS parameters should be comparable with stimulation protocols that modulate neuronal systems involved in motor cortical plasticity in animals.

Recent work with fMRI has confirmed early PET findings (Colebatch et al., 1991; Grafton et al., 1991, 1993) that multiple, overlapping sensorimotor representations of distinct hand movements exist in human primary motor cortex (Rao et al., 1995; Sanes et al., 1995; Indovina and Sanes, 2001). Plasticity of motor representations in the human motor cortex occurs after stroke (Liepert et al., 2000), amputation (Cohen et al., 1991), surgery (Duffau, 2001), learning (Karni et al., 1998), and modu- 


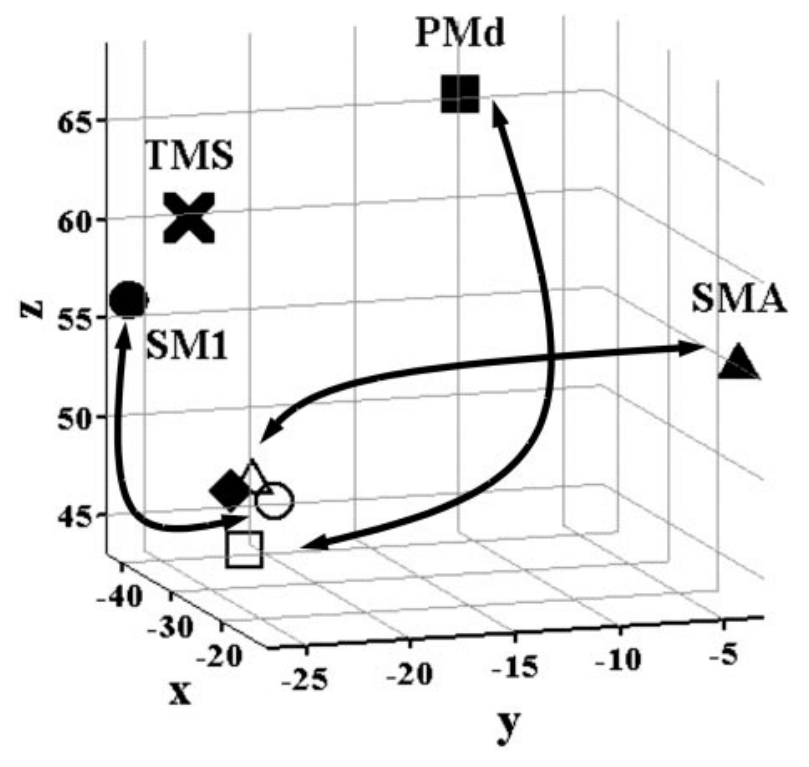

Figure 9. Three-dimensional representation of the relative positions of the primary motor cortex sites identified in the three PPI analyses shown in Figure $8 a-f$. The solid circle, square, and triangle symbols represent the regions of interest (the maxima of the main effect of movement) from which activity was used to create the PPI (see Materials and Methods). The open circle, square, and triangle symbols indicate the relative position of the sites in primary motor cortex that are more strongly influenced by activity in SM1, PMd, and SMA, respectively, after rTMS. The solid diamond indicates the position of the SM1 site seen in the movement-by-rTMS interaction (Fig. 6). X marks the site of stimulation with $1 \mathrm{~Hz}$ rTMS

lation of cortical excitability (Ziemann et al., 2002). It has been measured using functional imaging and transcranial and direct cortical stimulation.

Work in rat motor cortex confirms that within hours of motor nerve lesion (Donoghue et al., 1990) or repetitive intracortical microstimulation (Nudo et al., 1990), reorganization of cortical representations can be seen. In humans, reorganization of the motor strip, assessed using intraoperative electrical stimulation, has been reported within $30 \mathrm{~min}$ after tumor resection (Duffau, 2001). The reorganization within primary sensorimotor cortex seen in this study is in good agreement with a study by Ziemann et al. (2002) demonstrating a rapid remapping of body representations in the motor cortex after $0.1 \mathrm{~Hz}$ rTMS during transient deafferentation of the contralateral forearm.

The basis for cortical reorganization is thought to involve changes in cortical synaptic efficacy, through mechanisms such as long-term potentiation and long-term depression (Buonomano and Merzenich, 1998). The primary substrate for plasticity in the motor cortex is thought to be the intrinsic horizontal connections (Sanes and Donoghue, 2000). Repetitive low-frequency stimulation $(2 \mathrm{~Hz})$ induces LTD in these connections in rat motor cortex (Hess and Donoghue, 1996). This suggests that it is possible to modulate the neural substrate for map reorganization in motor cortex (intrinsic horizontal connections) using stimulation parameters similar to those used for rTMS. This result sits comfortably with our findings of decreased responses to cortical inputs within sensorimotor cortex.

This study adds to the body of evidence that low-intensity rTMS to the primary motor hand area induces long-lasting changes in neural activity in local and remote brain regions. However, the motor system is able to fully compensate for this by increasing activity in the contralateral premotor cortex, similar to that seen in stroke (Johansen-Berg et al., 2002). In addition, sites in primary sensorimotor cortex that are unlikely to have been affected by rTMS increase their movement-related activity and strengthen their connections with other components of the motor network, indicating an acute remodeling of motor representations within the primary sensorimotor cortex. Mapping these patterns of reorganization in the motor system provides a useful method for studying acute compensatory plasticity of the human brain and may help to understand how the brain reacts in response to more permanent lesions. To confirm that reorganization of motor representations occur during movement after rTMS and to provide further anatomical detail regarding the location of the sites of activation with regard to detailed motor maps, it may be necessary to use the superior spatial resolution of fMRI. This will be the subject of our next communication.

\section{References}

Abbott LF, Varela JA, Sen K, Nelson SB (1997) Synaptic depression and cortical gain control. Science 275:220-224.

Ackermann RF, Finch DM, Babb TL, Engel J Jr (1984) Increased glucose metabolism during long-duration recurrent inhibition of hippocampal pyramidal cells. J Neurosci 4:251-264.

Bohning DE, Shastri A, McGavin L, McConnell KA, Nahas Z, Lorberbaum JP, Roberts DR, George MS (2000) Motor cortex brain activity induced by $1-\mathrm{Hz}$ transcranial magnetic stimulation is similar in location and level to that for volitional movement. Invest Radiol 35:676-683.

Buonomano DV, Merzenich MM (1998) Cortical plasticity: from synapses to maps. Annu Rev Neurosci 21:149-186.

Chen R, Classen J, Gerloff C, Celnik P, Wassermann EM, Hallett M, Cohen LG (1997) Depression of motor cortex excitability by low-frequency transcranial magnetic stimulation. Neurology 48:1398-1403.

Cohen LG, Bandinelli S, Topka HR, Fuhr P, Roth BJ, Hallett M (1991) Topographic maps of human motor cortex in normal and pathological conditions: mirror movements, amputations and spinal cord injuries. Electroencephalogr Clin Neurophysiol [Suppl] 4336-4350.

Colebatch JG, Deiber MP, Passingham RE, Friston KJ, Frackowiak RS (1991) Regional cerebral blood flow during voluntary arm and hand movements in human subjects. J Neurophysiol 65:1392-1401.

Donoghue JP, Suner S, Sanes JN (1990) Dynamic organization of primary motor cortex output to target muscles in adult rats. II. Rapid reorganization following motor nerve lesions. Exp Brain Res 79:492-503.

Duffau H (2001) Acute functional reorganisation of the human motor cortex during resection of central lesions: a study using intraoperative brain mapping. J Neurol Neurosurg Psychiatry 70:506-513.

Enomoto H, Ugawa Y, Hanajima R, Yuasa K, Mochizuki H, Terao Y, Shiio Y, Furubayashi T, Iwata NK, Kanazawa I (2001) Decreased sensory cortical excitability after $1 \mathrm{~Hz}$ rTMS over the ipsilateral primary motor cortex. Clin Neurophysiol 112:2154-2158.

Fierro B, Piazza A, Brighina F, La Bua V, Buffa D, Oliveri M (2001) Modulation of intracortical inhibition induced by low- and high-frequency repetitive transcranial magnetic stimulation. Exp Brain Res 138:452-457.

Fitzgerald PB, Brown TL, Daskalakis ZJ, Chen R, Kulkarni J (2002) Intensity-dependent effects of $1 \mathrm{~Hz}$ rTMS on human corticospinal excitability. Clin Neurophysiol 113:1136-1141.

Fox P, Ingham R, George MS, Mayberg H, Ingham J, Roby J, Martin C, Jerabek P (1997) Imaging human intra-cerebral connectivity by PET during TMS. NeuroReport 8:2787-2791.

Friston KJ, Ashburner J, Poline JB, Frith CD, Heather JD, Frackowiak RSJ (1995a) Spatial registration and normalization of images. Hum Brain Mapp 2:165-189.

Friston KJ, Holmes AP, Worsley KJ, Poline JP, Frith CD, Frackowiak RS, (1995b) Statistical parametric maps in functional imaging: a general linear approach. Hum Brain Mapp 2:189-210.

Friston KJ, Buechel C, Fink GR, Morris J, Rolls E, Dolan RJ (1997) Psychophysiological and modulatory interactions in neuroimaging. NeuroImage 6:218-229.

Gerschlager W, Siebner HR, Rothwell JC (2001) Decreased corticospinal excitability after subthreshold $1 \mathrm{~Hz}$ rTMS over lateral premotor cortex. Neurology 57:449-455.

Grafton ST, Woods RP, Mazziotta JC, Phelps ME (1991) Somatotopic mapping of the primary motor cortex in humans: activation studies with cerebral blood flow and positron emission tomography. J Neurophysiol 66:735-743. 
Grafton ST, Woods RP, Mazziotta JC (1993) Within-arm somatotopy in human motor areas determined by positron emission tomography imaging of cerebral blood flow. Exp Brain Res 95:172-176.

Hess G, Donoghue JP (1996) Long-term depression of horizontal connections in rat motor cortex. Eur J Neurosci 8:658-665.

Indovina I, Sanes JN (2001) On somatotopic representation centers for finger movements in human primary motor cortex and supplementary motor area. NeuroImage 13:1027-1034.

Johansen-Berg H, Rushworth MF, Bogdanovic MD, Kischka U, Wimalaratna S, Matthews PM (2002) The role of ipsilateral premotor cortex in hand movement after stroke. Proc Natl Acad Sci USA 99:14518-14523.

Karni A, Meyer G, Rey-Hipolito C, Jezzard P, Adams MM, Turner R, Ungerleider LG (1998) The acquisition of skilled motor performance: fast and slow experience-driven changes in primary motor cortex. Proc Natl Acad Sci USA 95:861-868.

Kujirai T, Caramia MD, Rothwell JC, Day BL, Thompson PD, Ferbert A, Wroe S, Asselman P, Marsden CD (1993) Corticocortical inhibition in human motor cortex. J Physiol (Lond) 471:501-519.

Liepert J, Bauder H, Wolfgang HR, Miltner WH, Taub E, Weiller C (2000) Treatment-induced cortical reorganization after stroke in humans. Stroke 31:1210-1216.

Maeda F, Keenan JP, Tormos JM, Topka H, Pascual Leone A (2000) Modulation of corticospinal excitability by repetitive transcranial magnetic stimulation. Clin Neurophysiol 111:800-805.

Muellbacher W, Ziemann U, Boroojerdi B, Hallett M (2000) Effects of lowfrequency transcranial magnetic stimulation on motor excitability and basic motor behavior. Clin Neurophysiol 111:1002-1007.

Munchau A, Bloem BR, Irlbacher K, Trimble MR, Rothwell JC (2002) Functional connectivity of human premotor and motor cortex explored with repetitive transcranial magnetic stimulation. J Neurosci 22:554-561.

Nudo RJ, Masterton RB (1986) Stimulation-induced $\left[{ }^{14} \mathrm{C}\right] 2$-deoxyglucose labeling of synaptic activity in the central auditory system. J Comp Neurol 245:553-565.

Nudo RJ, Jenkins WM, Merzenich MM (1990) Repetitive microstimulation alters the cortical representation of movements in adult rats. Somatosens Mot Res 7:463-483.

Pascual Leone A, Tormos JM, Keenan J, Tarazona F, Canete C, Catala MD (1998) Study and modulation of human cortical excitability with transcranial magnetic stimulation. J Clin Neurophysiol 15:333-343.

Rao SM, Binder JR, Hammeke TA, Bandettini PA, Bobholz JA, Frost JA, Myklebust BM, Jacobson RD, Hyde JS (1995) Somatotopic mapping of the human primary motor cortex with functional magnetic resonance imaging. Neurology 45:919-924.

Romero JR, Anschel D, Sparing R, Gangitano M, Pascual Leone A (2002) Subthreshold low frequency repetitive transcranial magnetic stimulation selectively decreases facilitation in the motor cortex. Clin Neurophysiol 113:101-107.

Rossi S, Pasqualetti P, Rossini PM, Feige B, Ulivelli M, Glocker FX, Battistini
N, Lucking CH, Kristeva Feige R (2000) Effects of repetitive transcranial magnetic stimulation on movement-related cortical activity in humans. Cereb Cortex 10:802-808.

Sanes JN, Donoghue JP (2000) Plasticity and primary motor cortex. Annu Rev Neurosci 23:393-415.

Sanes JN, Donoghue JP, Thangaraj V, Edelman RR, Warach S (1995) Shared neural substrates controlling hand movements in human motor cortex. Science 268:1775-1777.

Seitz RJ, Hoflich P, Binkofski F, Tellmann L, Herzog H, Freund HJ (1998) Role of the premotor cortex in recovery from middle cerebral artery infarction. Arch Neurol 55:1081-1088.

Siebner HR, Rothwell J (2002) Transcranial magnetic stimulation: new insights into representational cortical plasticity. Exp Brain Res 148:1-16.

Siebner HR, Peller M, Willoch F, Minoshima S, Boecker H, Auer C, Drzezga A, Conrad B, Bartenstein P (2000) Lasting cortical activation after repetitive TMS of the motor cortex: a glucose metabolic study. Neurology 54:956-963.

Siebner HR, Takano B, Peinemann A, Schwaiger M, Conrad B, Drzezga A (2001) Continuous transcranial magnetic stimulation during positron emission tomography: a suitable tool for imaging regional excitability of the human cortex. NeuroImage 14:883-890.

Simpson EH (1949) Measurement of diversity. Nature 163:688.

Strafella AP, Paus T, Barrett J, Dagher A (2001) Repetitive transcranial magnetic stimulation of the human prefrontal cortex induces dopamine release in the caudate nucleus. J Neurosci 21:RC157(1-4).

Talairach J, Tournoux P (1988) Co-planar stereotaxic atlas of a human brain. Stuttgart: Thieme.

Terao Y, Ugawa Y (2002) Basic mechanisms of TMS. J Clin Neurophysiol 19:322-343.

Touge T, Gerschlager W, Brown P, Rothwell JC (2001) Are the after-effects of low-frequency rTMS on motor cortex excitability due to changes in the efficacy of cortical synapses? Clin Neurophysiol 112:2138-2145.

Tsuji T, Rothwell JC (2002) Long lasting effects of rTMS and associated peripheral sensory input on MEPs, SEPs and transcortical reflex excitability in humans. J Physiol (Lond) 540:367-376.

Wassermann EM, Grafman J, Berry C, Hollnagel C, Wild K, Clark K, Hallett M (1996) Use and safety of a new repetitive transcranial magnetic stimulator. Electroencephalogr Clin Neurophysiol 101:412-417.

Wassermann EM, Wedegaertner FR, Ziemann U, George MS, Chen R (1998) Crossed reduction of human motor cortex excitability by $1-\mathrm{Hz}$ transcranial magnetic stimulation. Neurosci Lett 250:141-144.

Weiller C, Chollet F, Friston KJ, Wise RJ, Frackowiak RSJ (1992) Functional reorganization of the brain in recovery from striatocapsular infarction in man. Ann Neurol 31:463-472.

Ziemann U, Wittenberg GF, Cohen LG (2002) Stimulation-induced within-representation and across-representation plasticity in human motor cortex. J Neurosci 22:5563-5571. y 